\title{
Thrombospondin-2 is upregulated in patients with aortic dissection and enhances angiotensin II-induced smooth muscle cell apoptosis
}

\author{
LIPING QI $^{1}$, KUI WU ${ }^{2}$, SHUTIAN SHI ${ }^{2}$, QINGWEI JI ${ }^{2}$, HUANGTAI MIAO $^{2}$ and QUE BIN $^{2}$ \\ ${ }^{1}$ Department of Cardiology, The Second Clinical Center, Chinese People's Liberation Army General Hospital, Beijing 100853; \\ ${ }^{2}$ Emergency and Critical Care Center, Beijing Anzhen Hospital, Capital Medical University, Beijing Institute of Heart, \\ Lung, and Blood Vessel Diseases, Beijing Lab for Cardiovascular Precision Medicine, Beijing 100029, P.R. China
}

Received August 22, 2019; Accepted April 1, 2020

DOI: $10.3892 /$ etm.2020.9279

\begin{abstract}
Thrombospondin-2 (TSP-2) is an important extracellular matrix protein that is involved in a variety of cardiovascular diseases, including viral myocarditis and abdominal aortic aneurysm. The present study aimed to investigate TSP-2 expression in patients with aortic dissection (AD). Aortas were obtained from patients with AD and healthy donors, and TSP-2 expression level in all samples was measured by western blotting and immunofluorescence assays. Blood samples were also collected from patients with AD and non-AD (NAD) subjects. Circulating TSP-2, tumor necrosis factor (TNF)- $\alpha$ and interleukin (IL)- 6 levels in each sample were detected using ELISAs. In addition, the effect of TSP-2 on angiotensin II (Ang II)-induced smooth muscle cell (SMC) apoptosis was assessed in vitro. Compared with healthy donors, aortic TSP-2 expression level was significantly increased in patients with AD. Furthermore, TSP-2 was secreted primarily by SMCs, but also by endothelial cells. TSP-2 plasma expression level was also elevated in patients with AD compared with non-AD subjects. Furthermore, TSP-2 serum expression level was positively correlated with TNF- $\alpha$ and IL-6 expression levels in patients with AD. In addition, recombinant mouse TSP-2 treatment increased Bax mRNA expression and decreased $\mathrm{Bcl} 2$ mRNA expression in Ang II-treated SMCs; however, the effects were reversed following treatment with the NF- $\mathrm{NB}$ p65 signaling pathway inhibitor JSH-23 or with the anti-TNF- $\alpha$ and anti-IL-6
\end{abstract}

Correspondence to: Dr Que Bin, Emergency and Critical Care Center, Beijing Anzhen Hospital, Capital Medical University, Beijing Institute of Heart, Lung, and Blood Vessel Diseases, Beijing Lab for Cardiovascular Precision Medicine, 2 Anzhen Road, Beijing 100029, P.R. China

E-mail: que_bin@126.com

Key words: aortic dissection, thrombospondin-2, NF-кB p65 signaling pathway, smooth muscle cell apoptosis, inflammatory response neutralizing antibodies. The present study demonstrated that TSP-2 expression was increased in the aortic tissues and plasma of patients with AD. These findings suggested that TSP-2 may participate in the progression of AD by activating the NF- $\mathrm{B}$ p65 signaling pathway and amplifying the inflammatory response.

\section{Introduction}

Aortic dissection (AD) is a vascular disease characterized by intramural hematoma following injury to the innermost layer of the aorta. AD has a low incidence rate but a high mortality rate. The mortality rate of patients with $\mathrm{AD}$ is $1-2 \%$ per hour before treatment after the dissection occurs and the total mortality rate is $>90 \%$ (1). Total aortic arch replacement and thoracic aortic intracavitary repair have been widely used for the clinical treatment of Stanford A type AD and Stanford B type AD, respectively; however, both treatment strategies display a number of limitations, among them, total aortic arch replacement is mostly applied to Stanford A type AD, with relatively few complications, but large trauma and high cost, which brings heavy psychological pressure and economic burden to patients and families; While intracavitary thoracic aortic repair is mostly applied to Stanford B type AD, which is relatively inexpensive but can significantly reduce short-term mortality $(2,3)$. Therefore, further investigation into the pathogenesis of $\mathrm{AD}$, as well as the identification of additional effective and safe targets are essential for the prevention and treatment of AD.

Thrombospondin-2 (TSP-2) is a multifunctional extracellular matrix protein that belongs to the TSP family (4). TSP-2 is widely expressed in organs and tissues in a variety of mammals, including humans and mice (5). Numerous studies have demonstrated that TSP-2 may be involved in the regulation of angiogenesis, proliferation, apoptosis, tumor migration, autophagy and transforming growth factor (TGF)- $\beta$ activation (4-8). Previous studies have also reported that TSP-2 can amplify the inflammatory response (9-11). Furthermore, the exact role of TSP-2 depends on the inflammatory microenvironment. For example, TSP-2 displays an anti-inflammatory role during chronic allograft nephropathy and viral myocarditis, 
whereas proinflammatory effects of TSP-2 have been observed during asthma (9-11).

Animal studies and clinical experiments have reported that TSP-2 expression is closely associated with the progression and development of a variety of cardiovascular diseases. For instance, circulating TSP-2 levels are increased in patients with chronic heart failure with or without preserved ejection fraction, and higher TSP-2 levels are associated with an increased frequency of cardiac events and poorer prognosis $(12,13)$. Elevated circulating TSP-2 levels are also observed in elderly patients with aortic aneurysms and are associated with increased mortality (14). Furthermore, TSP-2 knockout aggravates doxorubicin-induced cardiac injury and dysfunction (15) and prevents dilated cardiomyopathy in elderly mice (16). However, the expression of TSP-2 during human AD has not yet been reported. The present study aimed therefore to investigate TSP-2 expression during human AD and determine the underlying mechanisms.

\section{Materials and methods}

Sample collection. Aortic tissue and blood samples were collected from the Beijing Anzhen Hospital of Capital Medical University. The present study was approved by the Ethics Committee of Beijing Anzhen Hospital (approval no. $2017109 \mathrm{H})$. Written informed consent was obtained from all patients or their families.

Aortic tissue specimens (control group: Age, 3266; median age, 47; 6 males and 3 females and AD group: Age, 3974; median age 57; 12 males and 2 females) were collected by cardiac surgeons in the operating room of the Department of Anesthesiology of Anzhen Hospital between March 2016 and May 2018. Normal aortic specimens $(n=9)$ collected from brain dead donors who were involved in traffic accidents served as the control group. Donors with a history of significant cardiovascular diseases or aortic pathology changes were excluded. Torn aortic samples $(n=14)$ were obtained from patients who had been admitted for acute AD, according to clinical symptoms and results of computed tomography angiography (CTA), and who underwent surgical treatment. Torn aortic samples formed the AD group.

Blood samples of $\sim 2 \mathrm{ml}$ (control group: Age, 3365; median age, 43; 42 males and 18 females and AD group: Age, 4177, median age, 52; 132 males and 28 females) were obtained from patients in the intensive care unit of Anzhen Hospital between May 2017 and September 2018. Patients $(n=250)$ who were hospitalized due to sudden chest pain were enrolled in the present study. A total of 28 patients were excluded due to a history of diseases that have been reported to affect TSP-2 secretion, including chronic heart failure $(n=7)$, coronary artery disease $(n=3)$, peripheral vascular disease $(n=11)$, chronic renal failure $(n=4)$ and connective tissue disease $(n=3)$. A further two patients who were diagnosed with acute left heart failure caused by the development of pulmonary edema and dyspnea immediately after the onset of chest pain were also excluded. According to clinical diagnoses, the remaining 220 patients were divided into the non-AD (NAD) control group $(n=60)$ and the AD group $(n=160)$, which included the Stanford A group $(n=86)$ and the Stanford B group $(n=74)$. The patients in the NAD group were diagnosed with cervical spondylosis $(n=18)$, gastric erosion $(n=9)$, gastric ulcer $(n=9)$, cardiac neurosis $(n=13)$ or chest pain of unknown cause $(n=11)$.

All blood samples were obtained after CTA but prior to the administration of any treatment, as treatment, such as lowering the heart rate, lowering blood pressure or/and surgery may also affect TSP-2 secretion.

Western blotting. Total protein from each aortic specimen was extracted using RIPA buffer (cat. no. G2002-30; Wuhan Servicebio, Technology Co., Ltd.) and quantified using a bicinchoninic acid Protein Assay kit (Thermo Fisher Scientific, Inc.). A total of $30 \mu \mathrm{g}$ protein from each sample was separated by $8 \%$ SDS-PAGE and transferred to PVDF membranes at $100 \mathrm{~mA}$ for $2 \mathrm{~h}$. After blocking with $5 \%$ nonfat milk at $25^{\circ} \mathrm{C}$ for $90 \mathrm{~min}$, the membranes were incubated overnight at $4^{\circ} \mathrm{C}$ with primary antibodies targeted against TSP-2 ( $1 \mu \mathrm{g} / \mathrm{ml}$; cat. no. MAB1635; R\&D Systems, Inc.) and GAPDH (1:1,000; cat. no. 97166; Cell Signaling Technology, Inc.) at $4^{\circ} \mathrm{C}$ for $12 \mathrm{~h}$. Following primary incubation, the membranes were incubated with a secondary IRDye $800 \mathrm{CW}$-conjugated antibody (1:12,500; cat. no. 925-32210; Li-Cor Biosciences) at room temperature for $1 \mathrm{~h}$. Protein bands were scanned and quantified using an Odyssey Imaging system (LI-COR Biosciences).

Histological analysis. Aortic tissues were cut into appropriate sizes (1-3 $\left.\mathrm{mm}^{3}\right)$ immediately after dissection, and some specimens were immediately fixed in $4 \%$ paraformaldehyde at $25^{\circ} \mathrm{C}$ for 3 days. After embedding in paraffin, tissues were cut into 4-5 $\mu \mathrm{m}$ slices and placed on slides. After blocking with 5\% goat serum (cat. no. 16210072; Gibco; Thermo Fisher Scientific,Inc.) at room temperature for $5 \mathrm{~min}$, the slides were incubated with a primary anti-TSP-2 antibody $(0.5 \mu \mathrm{g} / \mathrm{ml}$; cat. no. BAF1635; R\&D Systems, Inc.). The sources of aortic TSP-2, including $\mathrm{CD}^{+} \mathrm{T}$ lymphocytes (CD4 ${ }^{+} \mathrm{TCs}$ ), macrophages (Møs), smooth muscle cells (SMCs) and endothelial cells (ECs), were investigated by double immunofluorescence staining. Slides were therefore incubated with the following primary antibodies: Anti-CD4 (20 $\mu \mathrm{g} / \mathrm{ml}$; cat. no. MAB379; R\&D Systems, Inc.), anti-CD68 (20 $\mu \mathrm{g} / \mathrm{ml}$; cat. no. MAB20401; R\&D Systems, Inc.), anti- $\alpha$-SMA $(15 \mu \mathrm{g} / \mathrm{ml}$; cat. no. MAB1420; R\&D Systems, Inc.) and anti-CD31 (20 $\mu \mathrm{g} / \mathrm{ml}$; cat. no. BBA7; R\&D Systems, Inc.). After incubation with anti-Mouse $\mathrm{IgG} \mathrm{H} \& \mathrm{~L}$ fragment (Alexa Fluor ${ }^{\circledR} 647$ Conjugate) secondary antibody $(1: 1,000$; cat. no. 4410; Cell Signaling Technology, Inc.) at room temperature for $90 \mathrm{~min}$, samples were observed using a fluorescence microscope (magnification, $\mathrm{x} 200$ ). The localization of TSP-2 expression could be observed by assessing whether the green and red signals merge together (yellow signals).

TSP-2, TNF- $\alpha$ and IL- 6 measurements. Blood samples were centrifuged at $5,000 \mathrm{x} \mathrm{g}$ at $4^{\circ} \mathrm{C}$ for $30 \mathrm{~min}$ and the the plasma of each sample collected and stored at $-80^{\circ} \mathrm{C}$ until further analysis. Prior to the measurement of cytokine levels, the supernatant samples were thawed and a preliminary test (ELISA) for dilution of different multiples was performed to determine the dilution ratio of the supernatant. After 5-fold dilution with deionized water, $100 \mu \mathrm{l}$ plasma solution was added to the plate and the TSP-2 (cat. no. DTSP20, R\&D Systems, Inc.), TNF- $\alpha$ (cat. no. KHC3014C; Thermo Fisher Scientific, Inc.) and IL-6 
(cat. no. EH2IL6; Thermo Fisher Scientific, Inc.) ELISA kits were used according to the manufacturer's protocol.

SMC isolation, culture and treatment. A total of 60 male C57BL/6 mice (age, 9-10 weeks; weight, 23-26 g) were purchased from the Institute of Model Zoology of Nanjing University and housed in a pathogen-free mouse room on a $12 \mathrm{~h}$ light $/ 12$ dark cycle at a temperature of $22-24^{\circ} \mathrm{C}$ and a humidity of $50 \pm 5 \%$ at Anzhen Hospital and received water ad libitum. Mice were anesthetized with $2 \%$ isoflurane and subsequently euthanized by cervical dislocation. The spleens, femurs and aortas were immediately isolated. CD4 ${ }^{+}$TCs $(17,18)$, bone marrow-derived Møs $(18,19)$, aortic SMCs $(20,21)$ and aortic ECs were isolated as previously described (22). Briefly, to obtain $\mathrm{CD}^{+}{ }^{+} \mathrm{TCs}$, a spleen cell suspension was prepared in complete RPMI-1640 culture medium (cat. no. 22400105; Gibco; Thermo Fisher Scientific, Inc.) and CD4 ${ }^{+}$TCs were positively selected using CD4 magnetic beads (Miltenyi Biotec, Inc.) and an auto-magnetic actived cell soring (MACS) separator. Furthermore, to obtain bone marrow-derived Møs, both ends of the femurs were cut and RPMI-1640 culture medium was used to flush out the cells from the femoral canal. Subsequently, red blood cells were lysed using ACK lysis buffer (cat. no. G2015-250; Wuhan Servicebio Technology Co., Ltd.), and the remaining cells were plated in 6-well plates $\left(10^{6}\right.$ cells per well) and treated with $50 \mathrm{ng} / \mathrm{ml}$ murine macrophage colony stimulating factor (cat. no. 315-02; PeproTech, Inc.) for 5 days at $37^{\circ} \mathrm{C}$ to promote Mø differentiation. For the isolation of aortic SMCs, the isolated aorta was treated with $0.1 \%\left(37^{\circ} \mathrm{C}\right)$ type II collagenase to remove the adventitia, and a sterile cotton-tipped applicator was used to gently remove the endothelium of the intima. The remaining aortic tissue was digested at $37^{\circ} \mathrm{C}$ with a mixture of $0.1 \%$ collagenase and $100 \mathrm{U} / \mathrm{ml}$ elastase to generate SMCs. Subsequently, a caliber 24 cannula was inserted into the proximal end of the ligated aorta and the inside of the aorta was washed with sterile PBS. The distal end was bound and the aorta was filled with $0.1 \%$ type II collagenase for $45 \mathrm{~min}$ at $37^{\circ} \mathrm{C}$. The inside of the aorta was washed with RPMI-1640 medium, and the medium was collected and centrifuged at $1000 \mathrm{x}$ g at $4^{\circ} \mathrm{C}$ for $15 \mathrm{~min}$ to obtain ECs. All isolated cells were cultured in RPMI-1640 medium supplemented with 10\% FBS (cat. no. 16140071; Gibco; Thermo Fisher Scientific, Inc.) and 1\% penicillin-streptomycin and placed at $37^{\circ} \mathrm{C}$ in a humidified incubator containing $5 \% \mathrm{CO}_{2}$.

Subsequently, $10^{6} \mathrm{CD} 4^{+} \mathrm{TCs}, 10^{6} \mathrm{Møs}, 10^{6} \mathrm{SMCs}$ and $10^{6}$ ECs were treated with $100 \mathrm{nM}$ Ang II for $12 \mathrm{~h}$. Control cells were incubated with saline. Additionally, different doses of Ang II (25, 50 or $100 \mathrm{nM}$; diluted in saline; cat. no. 05-23-0101; Sigma-Aldrich; Merck KGaA) or indomethacin $(10 \mu \mathrm{M}$, cat no. I7378; Sigma-Aldrich; Merck KGaA) were added to the $10^{6} \mathrm{SMC}$ culture at $37^{\circ} \mathrm{C}$ for $12 \mathrm{~h}$, as previously described (23). Groups were as follows: i) Saline; ii) $25 \mathrm{nM}$ Ang II; iii) $50 \mathrm{nM}$ Ang II; iv) $100 \mathrm{nM}$ Ang II; v) $100 \mathrm{nM}$ Ang II $+10 \mu \mathrm{M}$ indomethacin.

Furthermore, SMCs were grouped and treated as follows: i) Vehicle (0.1\% DMSO); ii) recombinant mouse TSP-2 (rmTSP-2; 30 ng/ml; R\&D Systems, Inc.); iii) TSP-2 + JSH-23 (15 $\mu \mathrm{M} ; \mathrm{NF}-\kappa \mathrm{B}$ p 65 signaling pathway inhibitor; Sigma-Aldrich; Merck KGaA); iv) TSP-2 + JSH-23 + mouse
anti-TNF- $\alpha$ neutralizing antibody (TNF- $\alpha \mathrm{nAb} ; 1 \mu \mathrm{g} / \mathrm{ml}$; R\&D Systems, Inc.); v) TSP-2 + JSH-23 + mouse anti-IL-6 neutralizing antibody (IL-6 nAb; $1 \mu \mathrm{g} / \mathrm{ml}$; R\&D Systems, Inc.); vi) Ang II (100 nM); vii) Ang II + TSP-2; viii) Ang II + TSP-2 + JSH-23; ix) Ang II + TSP-2 + JSH-23 + TNF- $\alpha$ nAb; and x) Ang II + TSP-2 + JSH-23 + IL-6 nAb. After incubation at $37^{\circ} \mathrm{C}$ for $12 \mathrm{~h}, \mathrm{mRNA}$ expression levels in SMCs were measured.

TSP-2, Bax and Bcl2 mRNA expression detection. Total RNA was extracted from CD4 ${ }^{+}$TCs, Møs, SMCs and ECs using TRIzol ${ }^{\circledR}$ reagent (Invitrogen; Thermo Fisher Scientific, Inc.). Total RNA was reverse transcribed to cDNA using a high-capacity cDNA reverse transcription kit (cat. no. 4368813; Thermo Fisher Scientific, Inc.) at $92^{\circ} \mathrm{C}$ for 5 min according to the manufacturer's protocol. Subsequently, qPCR was performed using LightCycler ${ }^{\circledR} 480$ SYBR-Green Master Mix (Roche Diagnostics). The following thermocycling conditions were used for the PCR: 35 cycles at $92^{\circ} \mathrm{C}$ for $30 \mathrm{sec}$ and $58^{\circ} \mathrm{C}$ for $40 \mathrm{sec}$, and $72^{\circ} \mathrm{C}$ for $35 \mathrm{sec}$. The primer pairs used for qPCR were validated in previous studies, and were as follows: TSP-2, forward: 5'-TGAGTTCCAGGGCACACCA-3'; reverse: 5'-GGCTTTCTGGGCAATGGTA-3'; Bax, forward: 5'-TTG CTGATGGCAACTTCAAT-3'; reverse: 5'-GATCAGCTC GGGCACTTTAG-3'; Bcl2, forward: 5'-CAGAAGATCATG CCGTCCTT-3'; reverse: 5'-CTTTCTGCTTTTTATTTCATG AGG-3' (24,25). mRNA levels were normalized to the internal reference gene GAPDH levels using the $2^{-\Delta \Delta \mathrm{Cq}}$ method (26).

Statistical analysis. Statistical analyses were performed using SPSS software (version 23.0; IBM Corp.). Categorical variables were presented as the count (\%) and continuous variables were presented as the median (interquartile range). Categorical data were analyzed using $\chi^{2}$ test and continuous variables were analyzed using Mann-Whitney U test. The Student's t-test was used to analyze differences between two groups. Comparisons among multiple groups were analyzed using Kruskal-Wallis followed by Dunn's post hoc test. Spearman's correlation analysis was used to identify correlations between TSP-2 expression level and TNF- $\alpha$ and IL- 6 expression levels in patients with AD. Multivariate regression analysis was used to assess the association between TSP-2 expression level and AD occurrence. $\mathrm{P}<0.05$ was considered to indicate a statistically significant difference.

\section{Results}

Comparison of clinical characteristics between the normal group and the $A D$ group. Compared with the normal group, patients in the AD group displayed significantly higher ages, D-dimer levels, white blood cell (WBC) counts and C-reactive protein (CRP) levels, but lower fasting glucose (Glu) levels. No significant differences were observed for the number of men, high blood pressure (HBP), smoking, lipid levels or creatinine (CREA) levels. In certain patients in the normal group, true blood pressure and heart rate (HR) measurements were not obtained as vital signs were being maintained with vasoactive drugs following severe traumatic brain injury. The clinical characteristics of the individuals in the normal and AD groups are presented in Table I. 
Table I. Clinical characteristics of subjects in the normal and AD groups.

\begin{tabular}{lccc}
\hline Characteristic & Normal & AD & P-value \\
\hline Gender (male/female) & $6 / 3$ & $12 / 2$ & 0.343 \\
Age $($ years $)$ & $46(34-58)$ & $11(73-65)$ & 0.004 \\
HBP $(\mathrm{n}, \%)$ & $5(55.6 \%)$ & $6(42.9 \%)$ & 0.363 \\
Smoking $(\mathrm{n}, \%)$ & $2(22.2 \%)$ & $5.9(4.6-6.9)$ & 0.400 \\
Glu $(\mathrm{mmol} / \mathrm{l})$ & $5.9(4.6-6.9)$ & $157(132-178)$ & 0.028 \\
SBP $(\mathrm{mmHg})$ & - & $94(78-101)$ & - \\
DBP $(\mathrm{mmHg})$ & - & $4.4(3.9-5.2)$ & - \\
TC $(\mathrm{mmol} / \mathrm{l})$ & $4.6(4.2-5.1)$ & $1.3(1.0-1.7)$ & 0.278 \\
TG $(\mathrm{mmol} / \mathrm{l})$ & $1.2(0.9-1.7)$ & $1.4(0.9-1.6)$ & 0.872 \\
HDL-C $(\mathrm{mmol} / \mathrm{l})$ & $1.5(1.0-1.8)$ & $2.2(1.7-2.8)$ & 0.509 \\
LDL-C $(\mathrm{mmol} / \mathrm{l})$ & $2.1(1.5-2.5)$ & $78(67-89)$ & 0.315 \\
HR $(\mathrm{bpm})$ & - & $79(68-91)$ & - \\
CREA $(\mu \mathrm{mol} / \mathrm{l})$ & $74(62-85)$ & $4.9(2.1-8.5)$ & 0.078 \\
D-dimer $(\mu \mathrm{g} / \mathrm{ml})$ & $1.4(0.8-2.1)$ & $12.2(8.9-15.7)$ & 0.008 \\
WBC $(\mathrm{x} 10 \% / \mathrm{l})$ & $6.1(4.9-7.6)$ & $11.9(2.7-17.9)$ & $<0.001$ \\
CRP $(\mathrm{mg} / \mathrm{l})$ & $0.5(0.2-2.2)$ & $<0.001$ \\
\hline
\end{tabular}

AD, aortic dissection; HBP, high blood pressure; Glu, fasting glucose; SBP, systolic blood pressure; DBP, diastolic blood pressure; TC, total cholesterol; TG, triglyceride; HDL-C, high density lipoprotein cholesterol; LDL-C, low density lipoprotein cholesterol; HR, heart rate; CREA, creatinine; WBC, while blood cell; CRP, C-reactive protein. - means no comparison due to lack of data availability.

Comparison of clinical characteristics between the NAD and $A D$ groups. The AD group displayed an increased number of men, as well as higher ages, smoking incidence, HBP incidence, systolic blood pressure, WBC counts, CRP levels and D-dimer levels, compared with the NAD group. Furthermore, the AD group displayed lower Glu levels compared with the NAD group. No significant differences were identified for other clinical characteristics, including diastolic blood pressure, lipid levels, HR, CREA levels and time, which was defined as the time interval between chest pain onset and collection of blood samples. In addition, no significant differences for the clinical characteristics were observed between the Stanford A and Stanford B groups. The clinical characteristics of patients in the NAD and AD groups are presented in Table II.

Aortic TSP-2 expression is increased in patients with AD. Aortic TSP-2 expression was detected by western blotting, and the results suggested that TSP-2 expression was $\sim 0.9$-fold higher in the AD group compared with the normal group (Fig. 1A). The results from the histological analysis displayed a similar trend, and TSP-2 expression in the AD group was increased compared with the control group (Fig. 1B). In addition, the results from double immunofluorescence staining indicated that aortic TSP-2 was localized in SMCs and at lower levels in ECs but was not expressed by $\mathrm{CD}^{+} \mathrm{TC}$ or Møs (Fig. 1C).

Circulating TSP-2, TNF- $\alpha$ and IL-6 levels are increased in patients with AD. Plasma TSP-2, TNF- $\alpha$ and IL-6 levels of each patient were measured by ELISA. The results demonstrated that TSP-2, TNF- $\alpha$ and IL-6 levels were significantly increased in the AD groups compared with the NAD group; however, no significant difference was observed between the Stanford A and Stanford B groups (Fig. 2A-C). In addition, Spearman's correlation analysis indicated that TSP-2 levels were positively correlated with TNF- $\alpha$ and IL- 6 levels in patients with AD (Fig. 2D and E).

TSP-2 is independently associated with AD occurrence. To investigate whether TSP-2 was associated with AD occurrence, univariate and multivariate linear regression analyses were performed. The results suggested that TSP-2 levels $(\beta=0.245 ; 95 \% \mathrm{CI}, 0.178-0.312 ; \mathrm{P}=0.006)$, TNF- $\alpha$ levels $(\beta=0.178 ; 95 \%$ CI, 0.139-0.217; $\mathrm{P}=0.014)$, IL-6 levels $(\beta=0.142$; 95\% CI, 0.107-0.177; $\mathrm{P}=0.026)$, HBP incidence $(\beta=0.133$; 95\% CI, 0.098-0.168; $P=0.039)$, Glu levels $(\beta=-0.131 ; 95 \%$ CI, -0.358- -0.096; $\mathrm{P}=0.032)$ and $\mathrm{D}$-dimer levels $(\beta=0.121$; 95\% CI, 0.091-0.151; $\mathrm{P}=0.047)$ were independently associated with AD occurrence. The results of the univariate and multivariate analyses are presented in Table III.

TSP-2 treatment increases Ang II-induced SMC apoptosis. Compared with saline treatment, Ang II treatment did not significantly alter TSP-2 mRNA expression levels in $\mathrm{CD}^{+}{ }^{+} \mathrm{TC}$ s or Møs. However, Ang II treatment significantly increased TSP-2 mRNA expression levels by 5.5 -fold in SMCs and 0.8-fold in ECs (Fig. 3A). In addition, Ang II treatment increased TSP-2 mRNA expression levels in SMCs in a dose-dependent manner, which was significantly inhibited by indomethacin (Fig. 3B). Furthermore, rmTSP-2 treatment significantly increased Ang II-induced Bax mRNA expression levels and decreased Bcl 2 mRNA expression levels in SMCs. In addition, the rmTSP-2-induced effects on SMCs were significantly reversed by JSH-23 treatment alone, and further 
Table II. Clinical characteristics of patients in the NAD and AD groups.

AD

\begin{tabular}{|c|c|c|c|c|}
\hline & & & & \\
\hline Characteristic & NAD & Total & Stanford A & Stanford B \\
\hline Sex (male/female) & $42 / 18(70.0)$ & $132 / 28^{a}$ & $74 / 10^{\mathrm{a}}$ & $58 / 18(78.4 \%)^{\mathrm{a}}$ \\
\hline Age (years) & $44(38-59)$ & $56(46-71)^{\mathrm{a}}$ & $54(44-69)^{\mathrm{a}}$ & $57(47-73)^{\mathrm{a}}$ \\
\hline Smoking (n, \%) & $14(23.3)$ & $62(38.8)^{\mathrm{a}}$ & $35(41.7)^{\mathrm{a}}$ & $27(36.5 \%)$ \\
\hline $\operatorname{HBP}(\mathrm{n}, \%)$ & $35(58.3)$ & $132(82.5)^{\mathrm{a}}$ & $71(84.5 \%)^{\mathrm{a}}$ & $61(82.4 \%)^{\mathrm{a}}$ \\
\hline Glu (mmol/l) & $5.9(4.9-7.3)$ & $5.3(4.1-6.7)^{\mathrm{a}}$ & $5.4(4.2-6.6)^{\mathrm{a}}$ & $5.2(4.0,6.9)^{\mathrm{a}}$ \\
\hline $\mathrm{SBP}(\mathrm{mmHg})$ & $149(132-163)$ & $159(146-170)^{\mathrm{a}}$ & $160(147-173)^{\mathrm{a}}$ & $158(145-168)^{\mathrm{a}}$ \\
\hline $\mathrm{DBP}(\mathrm{mmHg})$ & $84(75-101)$ & $88(82-105)$ & 87 (84-104) & $88(80-105)$ \\
\hline WBC $\left(\times 10^{9} / 1\right)$ & $6.4(5.2-7.7)$ & $10.9(8.5-13.1)^{\mathrm{a}}$ & $10.7(8.2-13.7)^{\mathrm{a}}$ & $11.2(8.9-12.8)^{\mathrm{a}}$ \\
\hline $\mathrm{TC}(\mathrm{mmol} / \mathrm{l})$ & $4.4(3.8-5.4)$ & $4.5(4.0-5.5)$ & $4.4(4.1-5.4)$ & $4.5(4.0-5.4)$ \\
\hline TG (mmol/l) & $1.0(0.8-1.3)$ & $1.1(0.9-1.4)$ & $1.1(0.9-1.5)$ & $1.0(0.9-1.3)$ \\
\hline HDL-C (mmol/l) & $1.1(0.8-1.4)$ & $1.2(0.9-1.5)$ & $1.1(0.9-1.4)$ & $1.2(0.8-1.5)$ \\
\hline LDL-C (mmol/l) & $1.6(1.1-1.9)$ & $1.5(1.1-2.0)$ & $1.6(1.1-2.1)$ & $1.5(1.0-2.0)$ \\
\hline $\mathrm{HR}(\mathrm{bpm})$ & $74(69-82)$ & $77(72-89)$ & $80(74-90)$ & $76(71-86)$ \\
\hline $\operatorname{CREA}(\mu \mathrm{mol} / \mathrm{l})$ & $85(72-96)$ & $90(68-100)$ & $89(71-104)$ & $91(65,98)$ \\
\hline CRP (mg/l) & $1.0(0.5-1.7)$ & $11.5(5.4-39.5)^{\mathrm{a}}$ & $14.6(3.9-32.5)^{\mathrm{a}}$ & $10.2(6.3-42.7)^{\mathrm{a}}$ \\
\hline D-dimer $(\mu \mathrm{g} / \mathrm{ml})$ & $0.8(0.2-1.2)$ & $5.9(3.9-9.5)^{\mathrm{a}}$ & $5.2(3.0-10.5)^{\mathrm{a}}$ & $6.4(4.5-8.5)^{\mathrm{a}}$ \\
\hline Time (h) & $10(7-14)$ & $12(6-16)$ & $11(6-16)$ & $12(7-15)$ \\
\hline
\end{tabular}

Time was defined as the time interval between chest pain onset and collection of blood samples. ${ }^{a} \mathrm{P}<0.05$ vs. the control group. NAD, non-AD; $\mathrm{AD}$, aortic dissection; HBP, high blood pressure; Glu, fasting glucose; SBP, systolic blood pressure; DBP, diastolic blood pressure; WBC, white blood cell; TC, total cholesterol; TG, triglyceride; HDL-C, high density lipoprotein cholesterol; LDL-C, low density lipoprotein cholesterol; $\mathrm{HR}$, heart rate; CREA, creatinine; CRP, C-reactive protein.

reversed by JSH-23 treatment combined with TNF- $\alpha$ nAb or IL-6 nAb (Fig. 3C).

\section{Discussion}

In the present study, TSP-2 expression was significantly higher in aortic tissues derived from patients with AD compared with healthy subjects. In addition, aortic SMCs and ECs, especially SMCs, were identified as the main sources of secreted TSP-2. Furthermore, circulating TSP-2 levels were higher in patients with AD compared with NAD subjects, and circulating TSP-2 levels were positively correlated with the circulating levels of the proinflammatory cytokines TNF- $\alpha$ and IL- 6 in patients with AD. Furthermore, circulating TSP-2 levels were independently associated with the occurrence of AD. Ang II treatment increased TSP-2 mRNA levels in SMCs in a dose-dependent manner in vitro, and Ang II-induced effects were reversed by indomethacin. By contrast, Ang II treatment displayed no effects on TSP-2 secretion in CD4 ${ }^{+}$TCs and Møs. TSP-2 treatment enhanced Ang II-induced SMC apoptosis, and JSH-23, TNF- $\alpha$ nAb and IL- 6 nAb treatment reversed the effects of TSP-2.

Clinical experiments and animal studies have demonstrated that TSP-2 expression is increased in a variety of cardiovascular diseases. For example, numerous studies have reported that serum TSP-2 levels are increased in patients with heart failure with preserved or reduced ejection fraction, elderly patients with aortic aneurysm and patients with aortic stenosis (12-14,27). In addition, TSP-2 expression levels are increased by 17 -fold in the heart tissue of patients with viral myocarditis compared with healthy heart tissue (10). Coxsackie virus exposure, doxorubicin treatment and aging also promote cardiac TSP-2 expression $(10,15,16)$. In the present study, TSP-2 expression was increased in plasma and aortic samples from patients with AD compared with healthy subjects, which suggested that TSP-2 was involved in AD occurrence.

TSP-2 is an extracellular matrix protein that, unlike inflammatory cytokines secreted by the immune system, is secreted primarily by innate cells in blood vessels and is also involved in the regulation of inflammatory responses (5). The immunofluorescence assay in the present study indicated that TSP-2 was primarily derived from SMCs and partly from ECs, but was not derived from CD4 ${ }^{+}$TCs or Møs, and Ang II-treated cells displayed similar trends in vitro, which was consistent with previous studies (9-11). Coxsackie virus and doxorubicin can induce strong cardiac immune and inflammatory responses. Cardiac TSP-2 expression is closely associated with the dose of Coxsackie virus, which suggests that the level of TSP-2 secretion is associated with the strength of the inflammatory response $(10,15)$. Ang II can mediate a strong inflammatory response and can be used to induce AD in mouse (28). In the present study, the effect of Ang II treatment on TSP-2 expression in SMCs was investigated, and the results suggested that Ang II increased TSP-2 mRNA expression in a dose-dependent manner. The addition of indomethacin, a non-specific and anti-inflammatory substance, reversed Ang II-induced effects on TSP-2 expression. The results were consistent with the aforementioned previous studies and 
A
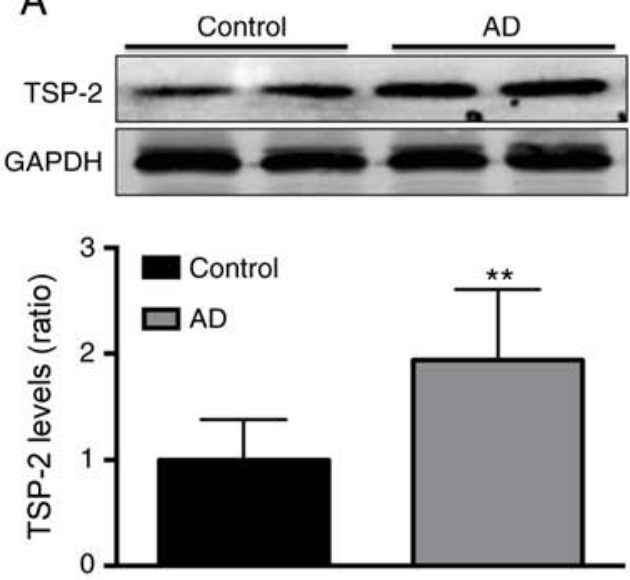

C

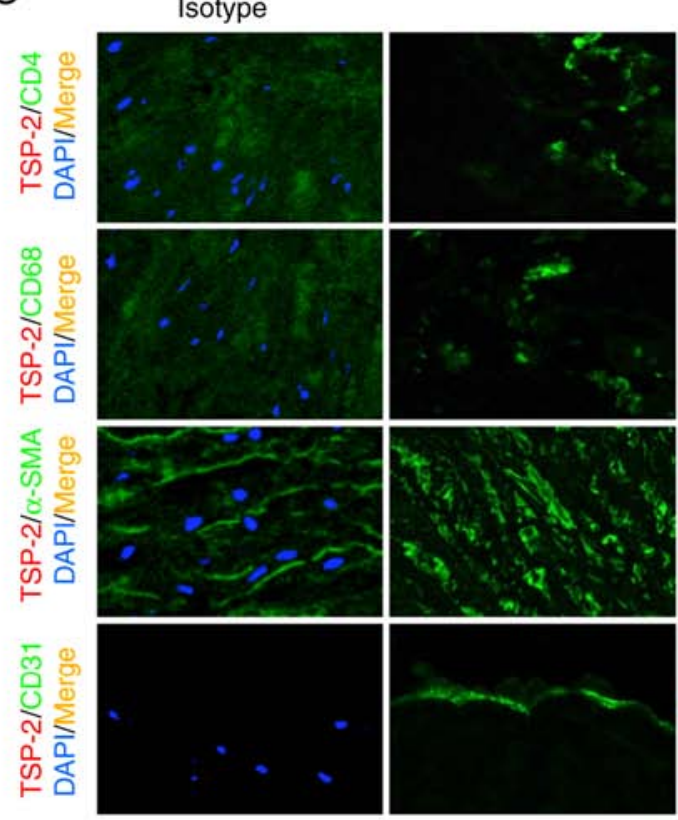

B

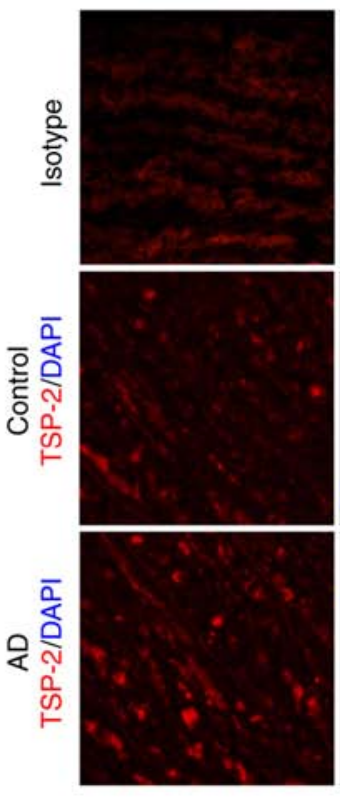

TSP-2

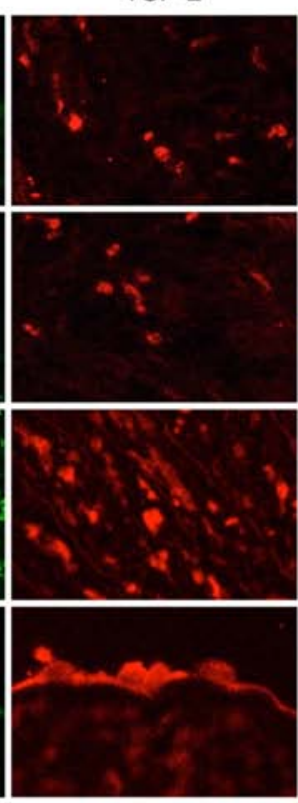

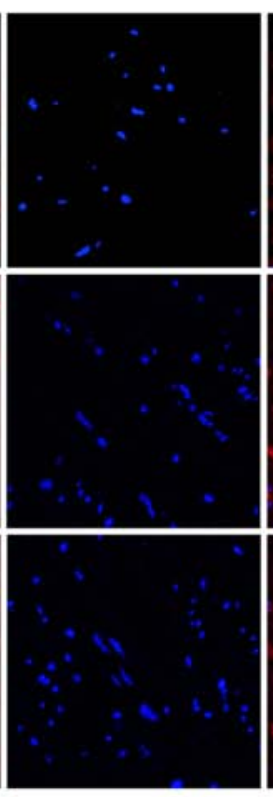

DAPI

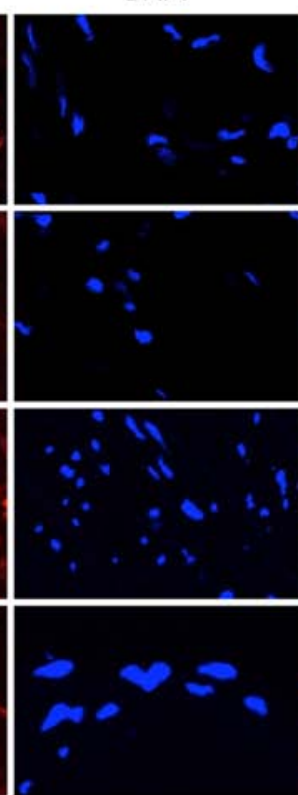

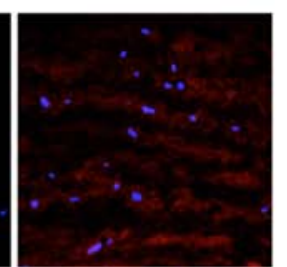

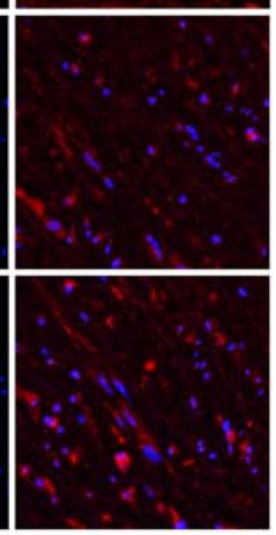

Merge

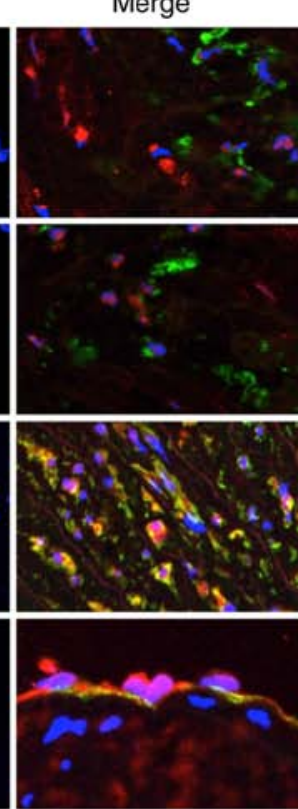

Figure 1. Aortic TSP-2 expression in patients with AD. (A) TSP-2 expression levels in the normal and AD groups were measured by western blotting. (B) TSP-2 expression levels in aortic tissue samples were assessed by immunofluorescence staining (magnification, x200). (C) Double immunofluorescence staining of aortic tissue samples with anti-CD68, anti-CD4, anti- $\alpha$-SMA and anti-TSP-2 antibodies (magnification, x200). TSP-2, thrombospondin-2; AD, aortic dissection; $\alpha$-SMA, $\alpha$-smooth muscle actin; AD, aortic dissection. ${ }^{* *} \mathrm{P}<0.01$ vs. the control group.

suggested that in the AD microenvironment, the inflammatory response may serve as an important factor mediating TSP-2 secretion.

Swinnen et al (16) reported that downregulation of TSP-2 expression by adeno-associated virus- 9 aggravates the inflammatory response in elderly mice. A subsequent study reported that TSP-2 downregulation regulates $\mathrm{CD} 4^{+} \mathrm{TC}$ differentiation and increases proinflammatory factor expression, while decreasing anti-inflammatory cytokine levels (15). Another study demonstrated that TSP-2 knockdown promotes inflammatory factor secretion in mice treated with doxorubicin (10). The results of the aforementioned studies indicated that TSP-2 could participate in cardiovascular diseases by regulating the inflammatory response. AD is a chronic inflammatory disease, which is characterized by increases in proinflammatory factor expression and decreases in anti-inflammatory factor expression in the aortic wall and plasma $(29,30)$. TNF- $\alpha$ and IL-6 are two inflammatory cytokines that have been reported to promote the progression of $\mathrm{AD}$ (30). To explore whether TSP-2 participated in AD by regulating the inflammatory response, circulating TNF- $\alpha$ and IL- 6 levels were measured in the present study, and the correlation between TNF- $\alpha$, IL-6 and TSP-2 expression levels in patients with AD were analyzed. The results indicated that TNF- $\alpha$ and IL-6 levels were positively correlated with TSP-2 levels, which supported the proposed hypothesis that TSP-2 may regulate the inflammatory response during AD; however, the role of TSP-2 during $\mathrm{AD}$ remains unclear. 
Table III. Univariate and multivariate linear regression analysis.

\begin{tabular}{|c|c|c|c|c|c|c|}
\hline \multirow[b]{2}{*}{ Variable } & \multicolumn{3}{|c|}{ Univariate } & \multicolumn{3}{|c|}{ Multivariate } \\
\hline & $\beta$ & $95 \% \mathrm{CI}$ & P-value & $\beta$ & $95 \% \mathrm{CI}$ & P-value \\
\hline TSP-2 (ng/ml) & 0.464 & $0.294-0.634$ & $<0.001$ & 0.245 & $0.178-0.312$ & 0.006 \\
\hline $\mathrm{TNF}-\alpha(\mathrm{pg} / \mathrm{ml})$ & 0.313 & $0.237-0.389$ & $<0.001$ & 0.178 & $0.139-0.217$ & 0.014 \\
\hline IL-6 (pg/ml) & 0.287 & $0.216-0.358$ & $<0.001$ & 0.142 & $0.107-0.177$ & 0.026 \\
\hline Male $(\mathrm{n}, \%)$ & 0.192 & $0.089-0.295$ & 0.042 & 0.084 & $0.038-0.130$ & 0.102 \\
\hline Age (years) & 0.204 & $0.102-0.306$ & 0.158 & - & - & - \\
\hline Smoking $(\mathrm{n}, \%)$ & 0.377 & $0.262-0.492$ & 0.098 & - & - & - \\
\hline $\operatorname{HBP}(\mathrm{n}, \%)$ & 0.109 & $0.058-0.160$ & 0.026 & 0.133 & $0.098-0.168$ & 0.039 \\
\hline Glu (mmol/l) & -0.218 & $-0.312--0.124$ & 0.012 & -0.131 & $-0.358--0.096$ & 0.032 \\
\hline $\mathrm{SBP}(\mathrm{mmHg})$ & 0.098 & $0.069-0.127$ & 0.518 & - & - & - \\
\hline WBC (x109/1) & 0.074 & $0.055-0.093$ & 0.414 & - & - & - \\
\hline $\mathrm{CRP}(\mathrm{mg} / \mathrm{l})$ & 0.215 & $0.124-0.306$ & 0.029 & 0.089 & $0.042-0.136$ & 0.374 \\
\hline $\mathrm{D}$-dimer $(\mu \mathrm{g} / \mathrm{ml})$ & 0.128 & $0.094-0.162$ & 0.009 & 0.121 & $0.091-0.151$ & 0.047 \\
\hline
\end{tabular}

CI, confidence interval; TSP-2, thrombospondin-2; TNF- $\alpha$, tumor necrosis factor- $\alpha$; IL-6, interleukin-6; HBP, high blood pressure; Glu, fasting glucose; SBP, systolic blood pressure; WBC, white blood cell; CRP, C-reactive protein; -, not applicable.
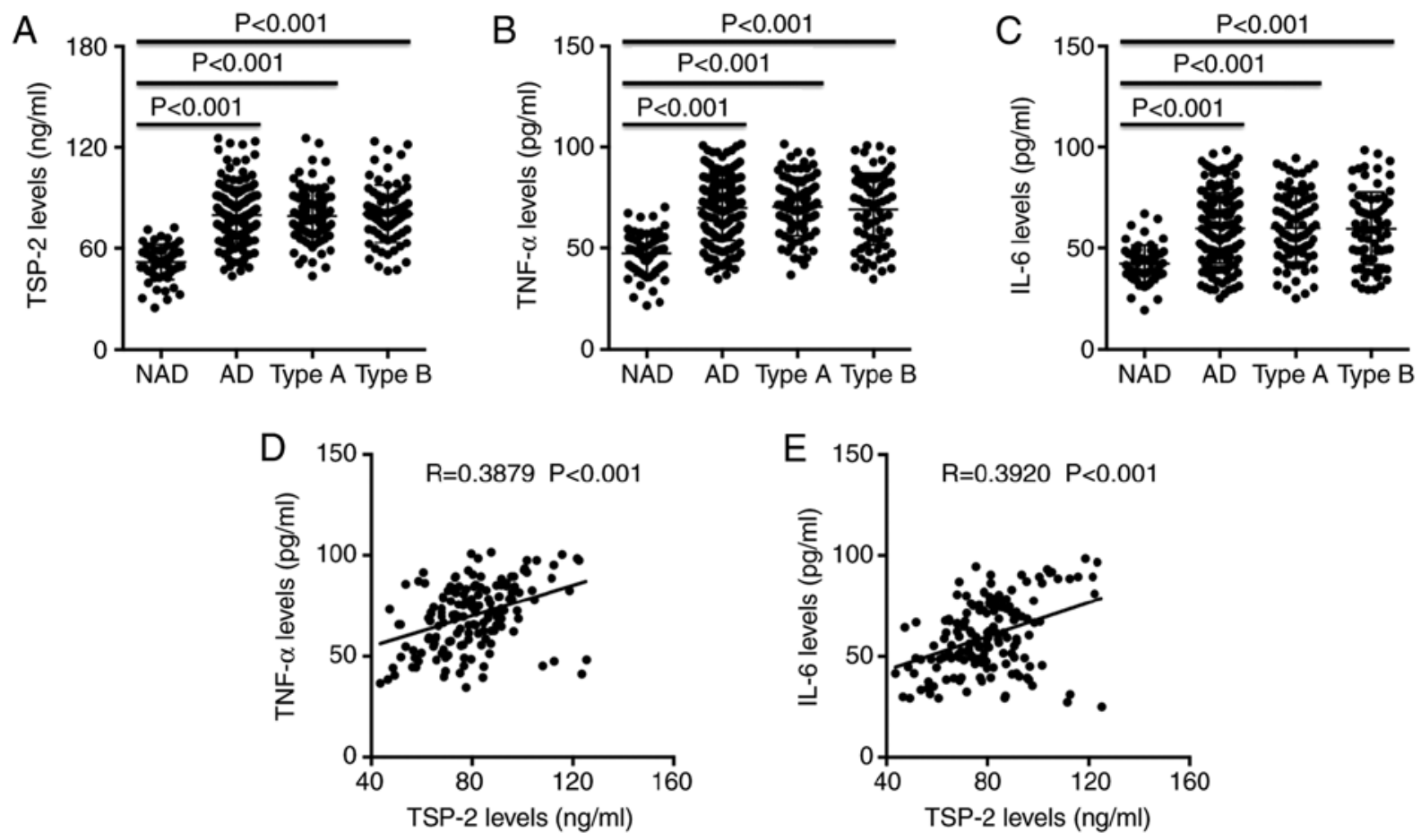

Figure 2. Circulating TSP-2 levels in patients with AD. (A) TSP-2, (B) TNF- $\alpha$ and (C) IL-6 circulating expression levels in the four different groups were detected by ELISA. Correlation between TSP-2 and (D) TNF- $\alpha$ or (E) IL-6 expression in patients with AD. TSP-2, thrombospondin-2; AD, aortic dissection; TNF- $\alpha$, tumor necrosis factor- $\alpha$; IL-6, interleukin-6; NAD, non-AD.

Vascular SMCs are important components of the aorta, accounting for $>90 \%$ of the total number of inherent cells. Extracellular matrix material secretion is critical for the maintenance of the normal structure and function of the aorta and for the dynamic balance of the matrix (31). It has been reported that patients with AD display excessive SMC apoptosis in aortic tissues, which releases myosin heavy chains into the blood to significantly increase the level of circulating myosin heavy chains $(21,32)$. The excessive loss of SMCs leads to the destruction of the dynamic balance of the extracellular matrix, resulting in structural and functional destruction of the aorta, which leads to increased susceptibility to $\operatorname{AD}(33,34)$. Therefore, excessive loss of SMCs is a fundamental factor of AD occurrence. In a recent study, Ye et al (29) reported that treatment of SMCs with plasma from patients with AD or patients with anti-inflammatory and proinflammatory 
A

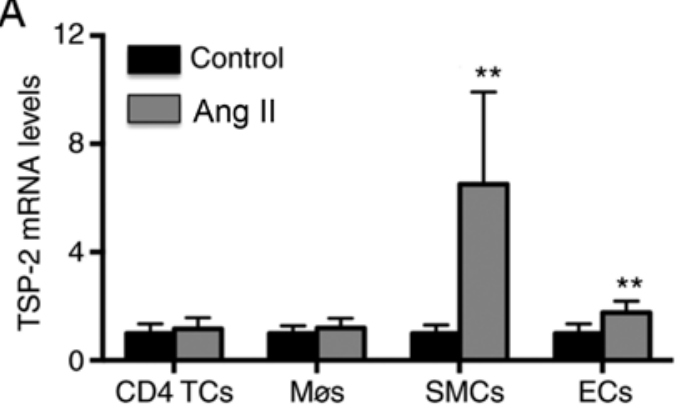

B

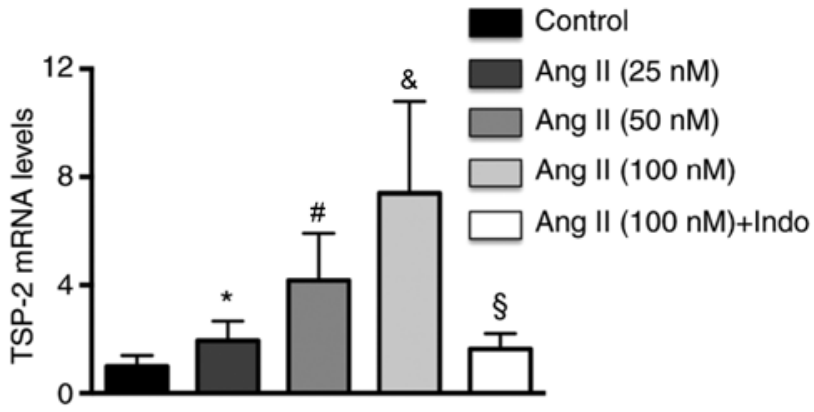

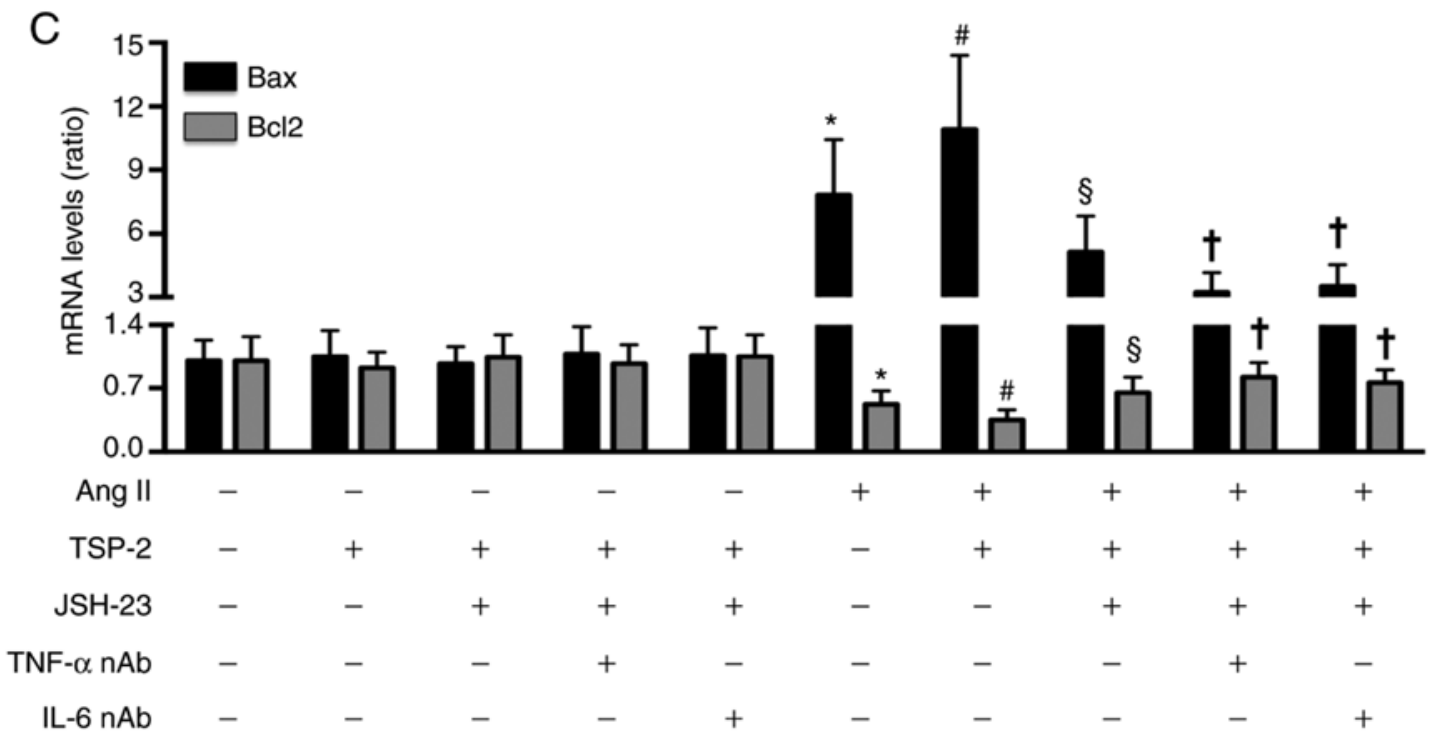

Figure 3. Effects of TSP-2 on Ang II-induced SMC apoptosis. (A) Effect of Ang II treatment on TSP-2 mRNA expression in CD4+ TCs, Møs, SMCs and ECs. ${ }^{* *} \mathrm{P}<0.01$ vs. the control group. (B) Effects of different doses of Ang II and Indo on TSP- 2 mRNA expression in SMCs. "P $<0.05$ vs. the negative control group. ${ }^{\#} \mathrm{P}<0.05$ vs. the Ang II $(25 \mathrm{nM})$ group. ${ }^{\&} \mathrm{P}<0.05$ vs. the Ang II $(50 \mathrm{nM})$ group. ${ }^{\circledR} \mathrm{P}<0.05$ vs. the Ang II $(100 \mathrm{nM})$ group. (C) Effects of TSP-2, JSH-23, anti-TNF- $\alpha$ $\mathrm{nAb}$ and anti-IL- $6 \mathrm{nAb}$ on Bax and Bcl 2 mRNA expression levels in SMCs. $\mathrm{n}=5$ per group. ${ }^{*} \mathrm{P}<0.05$ vs. the negative control group. ${ }^{*} \mathrm{P}<0.05$ vs. the Ang II group. ${ }^{\S} \mathrm{P}<0.05$ vs. the Ang II + TSP-2 group. ${ }^{\top} \mathrm{P}<0.05$ vs. the Ang II + TSP-2 + JSH-23 group. TSP-2, thrombospondin-2; Ang II, angiotensin II; TCs, T lymphocytes; Møs, macrophages; SMCs, smooth muscle cells; ECs, endothelial cells; Indo, indomethacin; TNF- $\alpha$, tumor necrosis factor- $\alpha$; IL-6, interleukin-6; nAb, neutralizing antibody; $\mathrm{AD}$, aortic dissection.

factor imbalance significantly increased Ang II-induced SMC apoptosis, suggesting that the inflammatory response is a key mechanism regulating excessive SMC apoptosis. To further explore the possible mechanisms underlying the involvement of TSP-2 during AD, Ang II-treated cells were also treated with rmTSP-2. The NF- $\mathrm{B}$ p65 signaling pathway is closely related to inflammatory regulation, and previous studies have confirmed that TSP-2 regulates downstream inflammatory signals by activating the $\mathrm{NF}-\kappa \mathrm{B}$ p65 signaling pathway $(28,35)$; therefore, JSH-23 was used to inhibit the NF- $\kappa$ B p65 signaling pathway in SMCs in the present study. The results indicated that TSP-2 treatment significantly increased Ang II-induced SMC apoptosis. Furthermore, the proapoptotic effect of TSP-2 was blocked by JSH-23 and further prevented by TNF- $\alpha$ or IL- 6 neutralization. The results suggested that TSP-2 may promote the expression of inflammatory factors and amplify their inflammatory effects by activating the NF- $\mathrm{B}$ p65 signaling pathway, thereby enhancing SMC apoptosis and positively regulating $\mathrm{AD}$ development. However, the aforementioned hypotheses require further investigation in vivo.

In conclusion, the present study suggested that TSP-2 may be closely related to the occurrence of AD, and TSP-2 downregulation may serve as a novel strategy for the prevention of $\mathrm{AD}$.

\section{Acknowledgements}

Not applicable

\section{Funding}

The present study was supported by the National Natural Science Foundation of China (grant no. 81770472).

\section{Availability of data and materials}

The datasets used and/or analyzed during the current study are available from the corresponding author on reasonable request.

\section{Authors' contributions}

QB conceived and designed the study; LQ and KW collected the samples; LQ, KW, SS and HM performed the experiments; QJ analyzed the data; LQ and KW were involved in drafting 
the manuscript and revising it critically for important intellectual content; QB reviewed and edited the manuscript. All authors read and approved the final manuscript.

\section{Ethics approval and consent to participate}

Both animal and human experiments in the present study were approved by the Ethics Committee of Beijing Anzhen Hospital (approval no. 2017109H). Written informed consent was obtained from all patients or their families.

\section{Patient consent for publication}

Not applicable.

\section{Competing interests}

The authors declare that they have no competing interests.

\section{References}

1. Hagan PG, Nienaber CA, Isselbacher EM, Bruckman D, Karavite DJ, Russman PL, Evangelista A, Fattori R, Suzuki T, Oh JK, et al: The international registry of acute aortic dissection (IRAD): New insights into an old disease. JAMA 283: 897-903, 2000.

2. Chen LW, Wu XJ, Lu L, Zhang GC, Yang GF, Yang ZW, Dong Y, Cao $\mathrm{H}$ and Chen Q: Total arch repair for acute type A aortic dissection with 2 modified techniques: Open single-branched stent graft placement and reinforcement of the dissected arch vessel stump with stent graft. Circulation 123: 2536-2541, 2011.

3. Fattori R,Cao P, De Rango P, Czerny M, Evangelista A, Nienaber C, Rousseau $\mathrm{H}$ and Schepens $\mathrm{M}$ : Interdisciplinary expert consensus document on management of type B aortic dissection. J Am Coll Cardiol 61: 1661-1678, 2013

4. Hugo C and Daniel C: Thrombospondin in renal disease. Nephron Exp Nephrol 111: e61-e66, 2009.

5. Calabro NE, Kristofik NJ and Kyriakides TR: Thrombospondin-2 and extracellular matrix assembly. Biochim Biophys Acta 1840: 2396-2402, 2014.

6. Rusnati M, Borsotti P, Moroni E, Foglieni C, Chiodelli P, Carminati L, Pinessi D, Annis DS, Paiardi G, Bugatti A, et al: The calcium-binding type III repeats domain ofthrombospondin-2 binds to fibroblast growth factor 2 (FGF2). Angiogenesis 22 : 133-144, 2019.

7. Morris AH, Stamer DK, Kunkemoeller B, Chang J, Xing H and Kyriakides TR: Decellularized materials derived from TSP2-KO mice promote enhanced neovascularization and integration in diabetic wounds. Biomaterials 169: 61-71, 2018.

8. Helkin A, Maier KG and Gahtan V: Thrombospondin-1, -2 and -5 have differential effects on vascular smooth muscle cell physiology. Biochem Biophys Res Commun 464: 1022-1027, 2015.

9. Daniel C, Vogelbacher R, Stief A, Grigo C and Hugo C: Long-term gene therapy with thrombospondin 2 inhibits TGF- $\beta$ activation, inflammation and angiogenesis in chronic allograft nephropathy. PLoS One 8: e83846, 2013.

10. Papageorgiou AP, Swinnen M, Vanhoutte D, VandenDriessche T, Chuah M, Lindner D, Verhesen W, de Vries B, D'hooge J, Lutgens E, et al: Thrombospondin-2 prevents cardiac injury and dysfunction in viral myocarditis through the activation of regulatory T-cells. Cardiovasc Res 94: 115-124, 2012.

11. Li K, Huang EP, Su J, Zhu P, Lin J, Luo SQ and Yang CL: Therapeutic role for TSP-2 antibody in a murine asthma model. In Arch Allergy Immunol 175: 160-170, 2018.

12. Kimura Y, Izumiya $Y$, Hanatani S, Yamamoto E, Kusaka H, Tokitsu T, Takashio S, Sakamoto K, Tsujita K, Tanaka T, et al: High serum levels of thrombospondin-2 correlate with poor prognosis of patients with heart failure with preserved ejection fraction. Heart Vessels 31: 52-59, 2016.

13. Hanatani S, Izumiya Y, Takashio S, Kimura Y, Araki S, Rokutanda T, Tsujita K, Yamamoto E, Tanaka T, Yamamuro $\mathrm{M}$, et al: Circulating thrombospondin-2 reflects disease severity and predicts outcome of heart failure with reduced ejection fraction. Circ J 78: 903-910, 2014.
14. Golledge J, Clancy P, Hankey GJ and Norman PE: Relation between serum thrombospondin-2 and cardiovascular mortality in older men screened for abdominal aortic aneurysm aneurysm. Am J Cardiol 111: 1800-1804, 2013.

15. van Almen GC, Swinnen M, Carai P, Verhesen W, Cleutjens JP, D'hooge J, Verheyen FK, Pinto YM, Schroen B, Carmeliet P and Heymans S: Absence of thrombospondin-2 increases cardiomyocyte damage and matrix disruption in doxorubicin-induced cardiomyopathy. J Mol Cell Cardiol 51: 318-328, 2011.

16. Swinnen M, Vanhoutte D, Van Almen GC, Hamdani N, Schellings MW, D'hooge J, Van der Velden J, Weaver MS, Sage EH, Bornstein P, et al: Absence of thrombospondin-2 causes age-related dilated cardiomyopathy. Circulation 120: 1585-1597, 2009.

17. Xiao L, Kirabo A, Wu J, Saleh MA, Zhu L, Wang F, Takahashi T, Loperena R, Foss JD, Mernaugh RL, et al: Renal denervation prevents immune cell activation and renal inflammation in angiotensin II-induced hypertension. Circ Res 117: 547-557, 2015.

18. Li Y, Zhang C, Wu Y, Han Y, Cui W, Jia L, Cai L, Cheng J, Li H and Du J: Interleukin-12p35 deletion promotes CD4 T-cell-dependent macrophage differentiation and enhances angiotensin II-Induced cardiac fibrosis. Arterioscler Thromb Vasc Biol 32: 1662-1674, 2012.

19. Lake FR, Noble PW, Henson PM and Riches DW: Functional switching of macrophage responses to tumor necrosis factor-alpha (TNF alpha) by interferons. Implications for the pleiotropic activities of TNF alpha. J Clin Invest 93: 1661-1669, 1994.

20. Golovina VA and Blaustein MP: Preparation of primary cultured mesenteric artery smooth muscle cells for fluorescent imaging and physiological studies. Nat Protoc 1: 2681-2687, 2006.

21. Jia LX, Zhang WM, Zhang HJ, Li TT, Wang YL, Qin YW, Gu H and $\mathrm{Du}$ J: Mechanical stretch-induced endoplasmic reticulum stress, apoptosis and inflammation contribute to thoracic aortic aneurysm and dissection. J Pathol 236: 373-383, 2015.

22. Kobayashi M, Inoue K, Warabi E, Minami T and Kodama T: A simple method of isolating mouse aortic endothelial cells. J Atheroscler Thromb 12: 138-142, 2005.

23. Ye J, Que B, Huang Y, Lin Y, Chen J, Liu L, Shi Y, Wang Y, Wang M, Zeng T, et al: Interleukin-12p35 knockout promotes macrophage differentiation, aggravates vascular dysfunction, and elevates blood pressure in angiotensin II-infused mice. Cardiovasc Res 115: 1102-1113, 2019.

24. Bae ON, Wang JM, Baek SH, Wang Q, Yuan H and Chen AF: Oxidative stress-mediated thrombospondin-2 upregulation impairs bone marrow-derived angiogenic cell function in diabetes mellitus. Arterioscler Thromb Vasc Biol 33: 1920-1927, 2013.

25. Xiao T, Zhang L, Huang Y, Shi Y, Wang J, Ji Q, Ye J, Lin Y and Liu H: Sestrin2 increases in aortas and plasma from aortic dissection patients and alleviates angiotensin II-induced smooth muscle cell apoptosis via the Nrf2 pathway. Life Sci 218: 132-138, 2019.

26. Livak KJ and Schmittgen TD: Analysis of relative gene expression data using real-time quantitative PCR and the 2(-Delta Delta C(T)) method. Methods 25: 402-408, 2001.

27. Pohjolainen V, Mustonen E, Taskinen $P$, Näpänkangas $J$, Leskinen H, Ohukainen P, Peltonen T, Aro J, Juvonen T, Satta J, et al: Increased thrombospondin-2 in human fibrosclerotic and stenotic aortic valves. Atherosclerosis 220: 66-71, 2012.

28. Ortega R, Collado A, Selles F, Gonzalez-Navarro H, Sanz MJ, Real JT and Piqueras J: SGLT-2 (Sodium-Glucose Cotransporter 2) inhibition reduces Ang II (Angiotensin II)-induced dissecting abdominal aortic aneurysm in ApoE (Apolipoprotein E) knockout mice. Arterioscler Thromb Vasc Biol 39: 1614-1628, 2019.

29. Ye J, Wang Y, Wang Z, Ji Q, Huang Y, Zeng T, Hu H, Ye D, Wan J and Lin Y: Circulating Th1, Th2, Th9, Th17, Th22, and treg levels in aortic dissection patients. Mediators Inflamm 2018: 5697149, 2018.

30. Zeng T, Shi L, Ji Q, Shi Y, Huang Y, Liu Y, Gan J, Yuan J, Lu Z, Xue Y, et al: Cytokines in aortic dissection. Clin Chim Acta 486: 177-182, 2018.

31. El-Hamamsy I and Yacoub MH: Cellular and molecular mechanisms of thoracic aortic aneurysms. Nat Rev Cardiol 6: 771-786, 2009. 
32. Suzuki T, Katoh H, Watanabe M, Kurabayashi M, Hiramori K, Hori S, Nobuyoshi M, Tanaka H, Kodama K, Sato H, et al: Novel biochemical diagnostic method for aortic dissection. Results of a prospective study using an immunoassay of smooth muscle myosin heavy chain. Circulation 93: 1244-1249, 1996.

33. Michel JB, Jondeau G and Milewicz DM: From genetics to response to injury: Vascular smooth muscle cells in aneurysms and dissections of the ascending aorta. Cardiovasc Res 114 578-589, 2018.

34. Ye P, Chen W, Wu J, Huang X, Li J, Wang S, Liu Z, Wang G, Yang X, Zhang P, et al: GM-CSF contributes to aortic aneurysms resulting from SMAD3 deficiency. J Clin Invest 123: 2317-2331, 2013.
35. De Stefano D, Nicolaus G, Maiuri MC, Cipolletta D, Galluzzi L, Cinelli MP, Tajana G, Iuvone T and Carnuccio R: NF-kappaB blockade upregulates Bax, TSP-1, and TSP-2 expression in rat granulation tissue. J Mol Med (Berl) 87: 481-492, 2009.

(i) $($ ) This work is licensed under a Creative Common Attribution-NonCommercial-NoDerivatives 4.0 International (CC BY-NC-ND 4.0) License. 